\title{
Math Timer: um objeto de aprendizagem para apoiar o ensino de Matemática
}

Marcelo de Melo Fernandes - marcelo.fernandes@dce.ufpb.br - CCAE/UFPB

Ayla Débora Dantas de Souza Rebouças - ayla@ dce.ufpb.br - CCAE/UFPB

Resumo. Muitos alunos terminam o ensino médio sem ter os conhecimentos esperados na área de matemática. Porém, ela é uma das áreas de conhecimento mais importantes para nós. Para tentar fazer com que os estudantes se envolvam mais com a Matemática e pratiquem mais os conteúdos, alguns professores estão inserindo jogos educativos no ensino de Matemática, uma vez que os jogos são vistos como uma atividade lúdica. Nesse sentido, este trabalho apresenta o Math Timer, um objeto de aprendizagem no estilo jogo e feito para apoiar o ensino de Matemática. Observou-se, até então, que o Math Timer pode auxiliar o processo de ensino-aprendizagem de Matemática, uma vez que foram obtidos bons resultados em uma avaliação feita com professores e alunos.

Palavras-chave: ensino de matemática, objetos de aprendizagem, jogos educacionais.

\section{Math Timer: a learning object to support the teaching of mathematics}

Abstract. Many students finish High School without the knowledge expected in mathematics. However, math is one of the most important knowledge areas for us. To try to make students become more involved with Mathematics and do more exercises, some teachers are introducing educational games in the teaching of Mathematics, since the games are seen as a playful activity. In this sense, this work presents Math Timer, a game-based learning object to support the teaching of mathematics. We have observed that Math Timer can support the teaching-learning process of math, according to some results obtained from an assessment with teachers and students.

keywords: math teaching, learning objects, educational games.

\section{Introdução}

A matemática é uma área de conhecimento de fundamental importância nas nossas vidas. Para Garcia (2009), a matemática desenvolve o pensamento lógico, auxilia na resolução de problemas e é útil na vida social. Ainda Segundo Garcia (2009), ensina-se matemática para dar oportunidades aos jovens de competir no mercado de trabalho, já que ela está presente em todos os tipos de concursos e provas de seleção. No entanto, de acordo com o site Todos pela Educação, apenas 9,3\% dos estudantes do $3^{\circ}$ ano do ensino médio apresentaram proficiência esperada em Matemática no ano de 2013, enquanto que $16,4 \%$ dos alunos do $9^{\circ}$ do ensino fundamental apresentaram proficiência esperada em Matemática. Por conta dessa preocupante estatística, percebe-se que muitos alunos terminam o ensino médio sem ter os conhecimentos esperados.

Uma possível proposta para minimizar esse problema é a utilização de softwares educacionais em sala de aula. Oliveira (2012) relata que a quase totalização das escolas possuem computadores, os quais podem ser utilizados como apoio a atividades V. $14 \mathrm{~N}^{\mathrm{o}} 1$, julho, 2016 
extraclasse. Além disso, várias crianças têm acesso a computadores, tablets ou smartphones atualmente e é importante fazer com que tais recursos possam ser utilizados não só para comunicação e entretenimento, mas também para promover o aprendizado.

Para Pinho et al. (2008), a informática traz uma nova forma de ensinar, através de uma dinâmica na qual o aluno, ao interagir com o software, pode ampliar sua motivação e obter uma melhoria significativa na sua aprendizagem. Uma forma de promover isso é por meio do m-learning, ou aprendizado móvel, que consiste no uso de tecnologias de rede sem fio para difundir o ensino e a aprendizagem, facilitando ainda mais o acesso a informações (Oliveira et al. 2007).

Considerando a grande dificuldade de muitos alunos com a matemática, a falta de interesse destes em fazer exercícios do modo tradicional e o potencial de impacto do uso de dispositivos móveis para apoiar a educação, este trabalho apresenta uma proposta de Objeto de Aprendizagem (OA) para o apoio ao processo de ensino-aprendizagem de Matemática voltado para dispositivos com Sistema Operacional Android. O OA foi chamado Math Timer e é um jogo do tipo Quiz que tem como ideia básica apresentar questões de múltipla escolha que precisam ser respondidas em um tempo limite. As questões apresentadas podem ser cadastradas em um sistema Web pelos professores.

Sendo assim, este artigo se foca no seguinte problema de pesquisa: qual o nível de aceitação do objeto de aprendizagem Math Timer com relação ao seu uso no apoio ao processo de ensino-aprendizagem de Matemática no Ensino Médio? Para responder a esta questão foi feito um estudo que teve como objetivo geral verificar o nível de aceitação do objeto de aprendizagem Math Timer com relação ao seu uso no apoio ao processo de ensino-aprendizagem de Matemática no Ensino Médio. O universo de estudo foi composto por alunos de ensino médio e professores de matemática da escola estadual Professor Luiz Gonzaga Burity e da escola municipal Antônia Luna Lisboa, todas escolas públicas e localizadas na cidade de Rio Tinto no Litoral Norte da Paraíba.

Além disso, buscou-se atingir também, por meio deste trabalho, aos seguintes objetivos específicos: a realização de uma pesquisa e análise de objetos de aprendizagem que são utilizados no processo de ensino-aprendizagem de Matemática; o desenvolvimento do objeto de aprendizagem Math Timer; a verificação do nível de uso das tecnologias atuais por alunos do Ensino Médio e professores de Matemática; e a verificação do nível de uso de objetos de aprendizagem por alunos do Ensino Médio e professores de Matemática.

As demais seções deste trabalho estão organizadas da seguinte forma: a Seção 2 apresenta a fundamentação teórica com alguns trabalhos relacionados; a Seção 3 apresenta os detalhes de implementação e características do objeto de aprendizagem Math Timer; a Seção 4 apresenta os resultados e as respectivas análises destes; e por último, na Seção 5 são apresentadas as conclusões e as propostas de trabalhos futuros.

\section{Metodologia}

Para a realização deste trabalho foi utilizada a abordagem metodológica de investigação conhecida como estudo de caso. Ventura (2007) afirma que o estudo de caso visa à investigação de um caso específico e delimitado, contextualizado em tempo e lugar para que se possa realizar uma busca circunstanciada de informações. Quanto ao tipo de pesquisa com relação aos objetivos, foi realizada uma pesquisa exploratória, 
pois de acordo com Gil (1991), ela visa proporcionar maior familiaridade com o problema.

De maneira geral, pode-se sintetizar que a metodologia utilizada neste trabalho consistiu nas seguintes atividades: finalização do OA; elaboração do instrumento de coleta de dados; coleta dos dados; levantamento bibliográfico; e análise dos dados coletados.

A coleta dos dados foi feita através de questionário aplicado com alunos ${ }^{1}$ do ensino médio e professores ${ }^{2}$ de Matemática. Esta coleta se deu da seguinte maneira: primeiramente, houve a apresentação do software para os alunos do $1^{\circ}, 2^{\circ}$ e $3^{\circ}$ anos do Ensino Médio. Depois foi distribuído um tablet para cada dupla de alunos, que ficaram jogando por aproximadamente 20 minutos. Após a utilização do software, os alunos responderam um questionário com 13 questões sobre o Math Timer e tiveram 25 minutos para responder todas as questões, porém todos terminaram a avaliação antes do tempo estabelecido. O conteúdo abordado no jogo foi o de Números Inteiros, por se tratar de um conteúdo do $6^{\circ}$ ano do ensino fundamental, e que se espera, portanto, que seja conhecido pelos alunos do ensino médio.

Para a coleta dos dados dos professores, primeiro houve a apresentação do software para cada professor. Posteriormente, os professores jogaram por aproximadamente 10 minutos. Após isso, foi feita a apresentação do site onde são cadastradas as questões mostradas no aplicativo. Depois da apresentação, eles foram convidados a cadastrar algumas questões. No final, os professores responderam um questionário com 10 questões para avaliarem o aplicativo e o seu serviço de cadastro de questões e não tiveram um tempo máximo estabelecido para responder as questões.

Para a realização da pesquisa de trabalhos relacionados, foi utilizada uma pesquisa estruturada, em que foi utilizada a seguinte chave de busca ("matemática" OR "math") AND ("ferramenta" OR "tool" OR "OA" OR "jogo" OR "game" OR "apoio" OR "support") no site da Comissão Especial de Informática na Educação da SBC (CEIE) que administra as seguintes revistas e anais de eventos: Revista Brasileira de Informática na Educação, Anais do Simpósio Brasileiro de Informática na Educação, Anais do Workshop de Informática na Escola, Anais dos Workshops do Congresso Brasileiro de Informática na Educação, Jornada de Atualização em Informática na Educação, Anais do Workshop de Desafios da Computação Aplicada à Educação. Como resultado da pesquisa apareceram 89 artigos como resultado da busca.

Na próxima etapa da pesquisa bibliográfica foi feita uma análise dos artigos pelo tema e pelo resumo, buscando os mais relevantes para este artigo. Ao final desta etapa, 15 artigos foram selecionados e tiveram as suas propostas analisadas. Os resultados obtidos com esse levantamento bibliográfico estão apresentados na Seção 3.

\section{Fundamentação Teórica}

Alguns educadores de Metamática têm ficado insatisfeitos com a forma como os conteúdos vêm sendo trabalhados em sala de aula, o que tem ampliado a procura por novos caminhos para tornar seu ensino algo realmente relevante à transformação do indivíduo e da sociedade (Pinho et al., 2008).

\footnotetext{
${ }^{1}$ https://www.dropbox.com/s/nq00cs64phupg6k/Questionario_alunos.docx?dl=0

${ }^{2} \mathrm{https} / / / \mathrm{www}$.dropbox.com/s/rcfrpujke04bsvn/Questionario_professores.docx?dl=0
} 
Nessa busca por novas formas de se apoiar o ensino, muitas vezes é feito o uso de softwares educacionais. Para Oliveira et al. (2001, apud Pinho et al. (2008)), um software é considerado educacional quando é inserido em um contexto de ensino e de aprendizagem para fins educacionais. Oliveira et al. (2001, apud Pinho et al. (2008)), relatam que qualquer programa de computador pode ser considerado como produto educacional, mesmo que originariamente, não tenha sido produzido com essa finalidade.

Cada vez mais tem-se utilizado o computador como recurso facilitador ao ensino de Matemática em todos os níveis de ensino. Benitti et al. (2010) destacam algumas finalidades quanto a sua utilização nas aulas de Matemática das séries do Ensino Fundamental, como: fonte de informação; auxílio no processo de construção de conhecimento; um meio para desenvolver autonomia pelo uso de softwares que possibilitem pensar, refletir e criar soluções.

Observando os softwares educacionais propostos nos trabalhos selecionados após a revisão bibliográfica realizada neste trabalho, foram observadas algumas características destes softwares, e que estão apresentadas na Tabela 1, considerando cada um deles: o tipo de plataforma em que o software foi designado para ser executado; se o software permite a realimentação das questões, ou seja, se o professor pode cadastrar mais questões para que o aluno responda; e se o software aborda apenas um conteúdo, ou se ele é flexível e permite trabalhar com vários conteúdos.

Tabela 1. Comparação entre os softwares analisados

\begin{tabular}{|l|l|l|l|}
\hline Nome & Plataforma & $\begin{array}{l}\text { Realimentação } \\
\text { de questões }\end{array}$ & $\begin{array}{l}\text { Conteúdo } \\
\text { abordado }\end{array}$ \\
\hline $\begin{array}{l}\text { Math Arrow (Martins et } \\
\text { al., 2015) }\end{array}$ & Android & Sim & Suporte a todos \\
\hline $\begin{array}{l}\text { BEM (Dantas et al., } \\
\text { 2013) }\end{array}$ & Multiplataforma & Não & Operações básicas \\
\hline $\begin{array}{l}\text { Brinquedos numéricos } \\
\text { (Pierini, 2012) }\end{array}$ & Não informada & Não & $\begin{array}{l}\text { Conjuntos } \\
\text { numéricos }\end{array}$ \\
\hline $\begin{array}{l}\text { Conquistando com o resto } \\
\text { (Santos et al., 2014) }\end{array}$ & $\begin{array}{l}\text { Dispositivos } \\
\text { móveis e desktop }\end{array}$ & Não & Divisão \\
\hline $\begin{array}{l}\text { Geogebra (Rocha et al., } \\
\text { 2008) }\end{array}$ & Multiplataforma & Não & $\begin{array}{l}\text { Geometria, } \\
\text { álgebra e cálculo }\end{array}$ \\
\hline $\begin{array}{l}\text { Pirâmide multiplicativa } \\
\text { Rolino et al., 2015) }\end{array}$ & $\begin{array}{l}\text { Dispositivos } \\
\text { móveis } \\
\text { multiplataforma }\end{array}$ & Não & Tabuada \\
\hline $\begin{array}{l}\text { Elica (Rocha et al., 2011) } \\
\text { Multiplataforma }\end{array}$ & Não & $\begin{array}{l}\text { Geometria } \\
\text { espacial }\end{array}$ \\
\hline $\begin{array}{l}\text { NumRac (Barbosa et al., } \\
\text { 2009) }\end{array}$ & Web & $\begin{array}{l}\text { Números } \\
\text { racionais/frações }\end{array}$ \\
\hline
\end{tabular}




\begin{tabular}{|c|c|c|c|}
\hline $\begin{array}{l}\text { PitagorasNet (pinho et al., } \\
\text { 2008) }\end{array}$ & Web & Não & $\begin{array}{l}\text { Teorema } \\
\text { Pitágoras }\end{array}$ \\
\hline $\begin{array}{l}\text { Questions today (Sena et } \\
\text { al., 2014) }\end{array}$ & Web & Não & Operações básicas \\
\hline $\begin{array}{l}\text { Supermercado virtual } \\
\text { (Benitti e Fiori. 2010) }\end{array}$ & Web & Não & $\begin{array}{l}\text { Matemática do } \\
\text { ensino } \\
\text { fundamental }\end{array}$ \\
\hline $\begin{array}{l}\text { Caféboo (Oliveira et al., } \\
\text { 2012) }\end{array}$ & $\begin{array}{l}\text { Web, mobile } \mathrm{e} \\
\text { multiplataforma }\end{array}$ & Não & Operações básicas \\
\hline $\begin{array}{l}\text { CriptoMat (Batista et al., } \\
\text { 2014) }\end{array}$ & Web & Não & $\begin{array}{l}\text { Conceitos } \\
\text { matemática }\end{array}$ \\
\hline $\begin{array}{l}\text { Desafio com palitos } \\
\text { (Santos et al., 2015) }\end{array}$ & $\begin{array}{l}\text { Android, } \\
\text { Blackberry } \\
\text { Windows Phone }\end{array}$ & Não & $\begin{array}{l}\text { Raciocínio } \\
\text { Lógico, } \\
\text { Algarismos } \\
\text { Romanos } \\
\text { Conversão } \\
\text { valores. } \\
\end{array}$ \\
\hline $\begin{array}{l}\text { Tabuada da Velha } \\
\text { (Henrique et al., 2015) }\end{array}$ & Web & Não & $\begin{array}{l}\text { Adição } \\
\text { subtração }\end{array}$ \\
\hline
\end{tabular}

Foram selecionados e analisados 15 softwares. Destes, observou-se que apenas 5 foram feitos para serem utilizados por dispositivos móveis. A maioria foi feita para ser utilizada em computadores convencionais. Quanto ao conteúdo abordado pelos softwares, 14 possuem o conteúdo já definido e não estão preparados para que se possa trabalhar outros conteúdos. Apenas o Math Arrow (Martins et al., 2015) permite uma maior flexibilidade com relação à escolha do assunto. O Math Arrow é também o único dentre os softwares analisados que permite a realimentação das questões por parte do professor. Nos outros programas, as questões utilizadas são sempre as mesmas.

Considerando a análise feita dos softwares educacionais para Matemática, observou-se que apenas o Math Arrow atendia aos requisitos que se esperava para o Math Timer e que foram: a capacidade de poder ser utilizado em dispositivos Android; a possibilidade de realimentação de questões; e o fato de poder abordar diferentes conteúdos. No entanto, o Math Timer diferencia-se do Math Arrow pela abordagem utilizada para obter as respostas do usuário para as questões de múltipla escolha propostas. No Math Arrow, o usuário deve acertar uma flecha na maçã com a resposta correta, sendo que as maçãs se movimentam na tela na direção de cima para baixo, o que acrescenta uma dificuldade extra ao jogo, enquanto que no Math Timer o usuário apenas seleciona a resposta desejada em um certo limite de tempo, conforme detalhado na Seção 4 apresentada a seguir.

\section{O Math Timer}

O principal objetivo do jogo Math Timer é apoiar alunos e professores no processo de ensino-aprendizagem, incentivando os professores a inserirem jogos 
educacionais em suas aulas ou em atividades extra-classe e estimulando os alunos a realizarem os exercícios de Matemática.

O Math Timer foi desenvolvido para ser usado em dispositivos com Sistema Operacional Android nas versões 2.3 ou superior e pode ser baixado gratuitamente através do site https://sites.google.com/a/dce.ufpb.br/mathtimer/home/download e todo o seu código fonte pode ser acessado através de um site de compartilhamento de projetos de software ${ }^{3}$. A escolha da plataforma Android se deve ao fato de esta ser uma plataforma móvel amplamente utilizada pelos brasileiros, como pode ser comprovado através de pesquisa realizada pela empresa de consultoria Kantar WorldPanel.

$\mathrm{O}$ professor insere as questões através de um site ${ }^{4}$ onde atribui um rótulo para cada conteúdo ou conjunto de questões, como por exemplo, "Questões sobre números inteiros", e automaticamente estas questões são salvas em um banco de dados online. É importante destacar que para cada questão se pode inserir uma imagem de apoio. Além disso, são cadastrados o enunciado e as alternativas. Através do aplicativo Math Timer e com uma conexão com a Internet, os alunos conseguem fazer o download destas questões. Por outro lado, para jogar não é necessário estar conectado à Internet. Portanto, as principais características do Math Timer são: disponibilidade para dispositivos Android; possibilidade de trabalhar com diversos conteúdos; e a inserção dos conteúdos pelo próprio professor.

\subsection{Funcionalidades e Telas}

O Math Timer propõe que o jogador escolha a resposta para uma pergunta apresentada como desafio dentro de um prazo limite medido por um timer ilustrado na parte superior da tela do jogo e que vai sendo decrementado, conforme ilustrado na Figura 1. Este timer foi introduzido para estimular o aluno a responder as questões mais rapidamente. Logo abaixo do timer é mostrada a pontuação atual do aluno. Ao lado da pontuação, temos a pergunta que o aluno terá de responder, e logo abaixo da pergunta, temos as respostas disponíveis, onde o aluno deverá selecionar a resposta correta. Se o aluno selecionar uma resposta incorreta, aparece uma mensagem informando que aquela não é a resposta correta, mas o jogo continua e o aluno ganhará uma pontuação menor naquela questão caso acerte em uma nova tentativa. A pontuação de cada questão ocorre da seguinte maneira: se o aluno acertar na primeira tentativa ganha 10 pontos; se o aluno acertar na segunda tentativa ele ganhará 7 pontos; acertando na terceira tentativa ganha 3 pontos; e acertando na quarta tentativa ou superior ganhará 1 ponto.
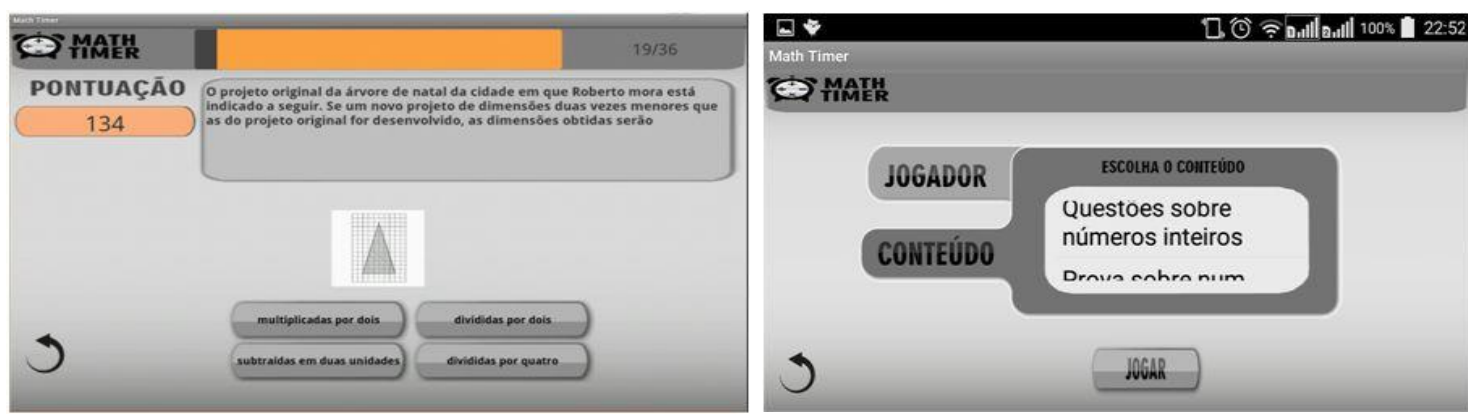

Figura 1. Telas do jogo do Math Timer

\footnotetext{
${ }^{3}$ https://github.com/marcelofernandes/mathtimer.git

${ }^{4} \mathrm{http}: / /$ mathtimerproext.rhcloud.com/
} 
Uma das limitações da versão atual da ferramenta é que no enunciado só é possível colocar texto, portanto, não é possível colocar, por exemplo, formas geométricas. Mas essa limitação pode ser minimizada com a inserção de uma imagem que aparecerá logo abaixo do enunciado, como pode ser observado ainda na Figura 1.

O aluno pode baixar vários conjuntos de questões e na hora de jogar ele escolhe qual ele deseja jogar, como se pode ver na segunda tela da Figura 1. Porém, para baixar novos conteúdos, é necessário estar conectado à Internet. Outra funcionalidade existente é que o usuário pode remover conjuntos de questões que ele não queira mais exercitar no jogo, apenas pressionando sobre o nome do conteúdo desejado numa lista de conteúdos instalados.

Na Tela de Menu, há a opção de baixar um conteúdo online, para ser jogado posteriormente, bem como há a opção de remover alguns conteúdos que já estejam cadastrados. Outra funcionalidade que pode ser acessada pela Tela de Menu é a visualização do Ranking com as 5 maiores notas separadas por conteúdo. Cada dispositivo móvel possui o seu ranking específico, não sendo possível visualizar o ranking de outros dispositivos. Nesta tela também é possível verificar as instruções do jogo, caso o aluno tenha alguma dificuldade quanto ao funcionamento do jogo.

\section{Avaliação}

A avaliação do Math Timer foi realizada com 65 alunos de cinco turmas de ensino médio, sendo duas turmas do $1^{\circ}$ ano, uma turma do $2^{\circ}$ ano e duas turmas do $3^{\circ}$ ano, todas da Escola Estadual de Ensino Fundamental e Médio Professor Luiz Gonzaga Burity. A avaliação também foi feita com 7 professores de Matemática, sendo quatro professores desta mesma escola e três professores da Escola Municipal de Ensino Fundamental e Médio Antônia Luna Lisboa. Ambas as escolas são públicas e estão localizadas em Rio Tinto, no litoral norte da Paraíba.

A seguir é apresentada uma análise detalhada dos resultados obtidos na avaliação do Math Timer com os professores e os alunos.

\subsection{Avaliação com alunos}

Fazendo-se uma análise quanto ao nível de uso das tecnologias atuais por parte dos alunos, foi constatado que a grande maioria dos alunos (61/65 alunos ou 94\%) tinham familiaridade com o computador, sendo que $51 / 65$ alunos ou $78 \%$ possuiam smartphone, $47 \%$ (31/65 alunos) possuiam tablet e 21\% (14/65 alunos) possuiam notebook. Portanto, percebe-se que grande parte dos alunos fazem uso das TICs dos dias atuais. Dos alunos que possuíam dispositivos móveis, 81\% (53/65 alunos) costumam instalar jogos e aplicativos, mas apenas 42\% (27/65 alunos) já usaram jogo educativo. Como se pode perceber, embora a maioria dos alunos estejam inseridos no mundo digital, menos da metade (27/65 alunos $42 \%)$ faz uso destas tecnologias em favor da educação.

Com relação à experiência dos alunos na utilização de jogos educativos no ensino-aprendizagem, a maioria dos alunos (59/65 alunos ou 91\%) acham que a utilização de jogos ajuda no aprendizado de Matemática. Ainda 68\% (44/65) dos alunos gostariam de ter usado jogos educativos para aprender Matemática.

De acordo com avaliação dos alunos quanto aos aspectos do aplicativo, 94\% (61/65) dos alunos acharam o jogo divertido e ainda 95\% (62/65) gostaram do design do 
jogo. Todos os alunos avaliados (65/65 alunos ou 100\%) entenderam o funcionamento do jogo sem precisar de ajuda, o que mostra que o jogo é intuitivo. A maioria dos alunos (54/65 alunos ou 83\%) sentiram vontade de jogar novamente, o que reforça a ideia de que é um jogo divertido. A nota média para o jogo, dada pelos alunos, foi de 8,9 , de uma escala de 1 a 10. E a quase totalidade dos alunos (63/65 alunos ou 97\%) recomendariam a utilização deste jogo a outros alunos. Tais resultados dão indícios de que o objeto de aprendizagem Math Timer foi bem aceito pelos estudantes como instrumento para apoiar o ensino-aprendizagem de Matemática.

\subsection{Avaliação com professores}

Quanto ao nível de uso das tecnologias atuais por parte dos professores, todos os professores (7/7 professores ou 100\%) afirmaram ter familiaridade quanto ao uso do computador. Constatou-se também que todos os professores (7/7 professores ou 100\%) possuíam smartphone e notebook, e ainda 86\% (6/7) deles possuíam tablet. Portanto, percebe-se que, assim como os alunos, os professores também fazem uso das TICs atuais. Apesar disso, pouco mais da metade (4/7 professores ou 57\%) dos professores relataram que utilizam o computador na educação, como ferramenta de apoio ao ensino-aprendizagem. Porém, apenas 29\% (2/7) dos professores afirmaram que fazem uso do laboratório de informática em suas aulas. Isso mostra que, embora os professores tenham um bom domínio das tecnologias atuais, eles não utilizam com frequência no apoio às suas aulas.

Considerando a experiência dos professores na utilização de jogos educativos para o ensino-aprendizagem de Matemática, todos os 7 professores acreditam que a utilização de jogos ajuda no aprendizado de matemática. Além disso, 86\% (6/7) dos professores afirmaram já terem feito a utilização de algum objeto de aprendizagem para apoiar o ensino de Matemática. No que diz respeito à avaliação do aplicativo pelos professores, todos os professores gostaram do design da ferramenta. Outro aspecto observado foi que todos os professores aprovaram a opção de o professor poder cadastrar as questões para o aluno utilizar no aplicativo. Além disso, todos os professores afirmaram que recomendariam a utilização do Math Timer a outros professores.

\subsection{Sugestões de melhoria do Math Timer}

Durante a avaliação, foi pedido para que os alunos e professores contribuíssem com ideias para melhorar o Math Timer. Dentre todas as melhorias sugeridas, as que mais se destacam são: colocar níveis de dificuldade para as questões, ou seja, o usuário poderia escolher entre jogar no nível fácil, médio ou difícil; melhorar o visual gráfico do jogo; utilizar cores mais vivas no jogo, ao invés da predominância de tons de cinza; permitir que o jogo tenha o modo multijogador, onde uma mesma partida possa ser jogada por vários jogadores; e permitir que o jogo possa fornecer feedback ao professor sobre o desempenho de cada aluno.

\section{Conclusões e Trabalhos Futuros}

Esse trabalho deu indícios que tanto os alunos quanto os professores pesquisados vivem conectados no mundo digital, utilizando-se ativamente das tecnologias de informação e comunicação atuais. Por outro lado, observou-se que os alunos e 
professores pesquisados utilizam pouco essas tecnologias em favor do processo de ensino-aprendizagem.

É importante destacar que todos os objetivos propostos foram alcançados, já que foi feita a identificação de outros objetos de aprendizagem que são utilizados para o apoio ao ensino-aprendizagem de Matemática no Ensino Médio, e foi feito o desenvolvimento do Math Timer e sua avaliação. Considerando que o Math Timer teve um bom nível de aceitação por parte dos alunos e professores, há indícios de que o Math Timer é capaz de apoiar o ensino-aprendizagem de Matemática no Ensino Médio.

São previstos como trabalhos futuros, contudo, o desenvolvimento das melhorias sugeridas durante a avaliação, principalmente o desenvolvimento de um sistema de feedback que retornasse informações sobre o desempenho dos alunos para os professores. Prevê-se também que no cadastro das questões se configure o tempo esperado para cada questão e que possa ser disponibilizado um ranking geral de todos os alunos, como forma de motivá-los.

\section{Agradecimentos}

Gostaríamos de agradecer aos professores Carlos Alberto Gomes de Almeida e Marcus Williams Aquino de Carvalho pela sua contribuição na revisão deste trabalho.

\section{Referências}

Barbosa, E. F., Maneghetti, R. C. e Ponte, L. (2009) NUMRAC - Um Objeto de Aprendizagem como Apoio ao Ensino de Matemática. In: XXII Simpósio Brasileiro de Informática na Educação - SBIE. Florianópolis - SC. p.1683-1692.

Batista, B. J. S., Lazari, P. E. S., Barvinski, C. A., Odakura, V. e Sanabria, L. (2014) CriptoMat2: ensinando Matemática utilizando conceitos de Criptografia - em bloco e RSA. In: Anais dos Workshops do CBIE.

Benitti, F. B. V. and Fiori, T. F. (2010) Supermercado Virtual: software educacional de matemática para o Ensino Fundamental. In: Anais do WIE.

Dantas, A. L. P., Pinto, G. R. R., e Sena, C. P. P. (2013). Apresentando o BEM: Um Objeto de Aprendizagem para mediar o processo educacional de crianças com deficiência visual e videntes nas operações básicas de Matemática. In Anais do Simpósio Brasileiro de Informática na Educação (Vol. 24, No. 1).

Garcia, V. C. V. (2009) Fundamentação teórica para as perguntas primárias: O que é matemática? Por que ensinar? Como se ensina e como se aprende? Educação, Porto Alegre, v. 32, n. 2, p. 176-184.

Gil, A. C. (1991) Como elaborar projetos de pesquisa. 3. ed. São Paulo: Atlas.

Henrique, M. S., Morais, I. S., Azevedo, S. P. e Albuquerque, V. F. A. (2015) Tabuada da Velha: Um Jogo Educacional Sobre Adição e Subtração. In: Anais dos Workshops do CBIE.

Martins, F. S., Dantas, A. e Alves, E. S. (2015) Apoiando o ensino-aprendizagem de matemática usando o Math Arrow. In: Anais do LACLO.

Oliveira, L.R.,and Medina, R.D. (2007) Desenvolvimento de objetos de aprendizagem para dispositivos móveis: uma nova abordagem que contribui para a educação. RENOTE- Revista Novas Tecnologias na Educação. Porto Alegre, 5, n. 1, 01 - 12. 
Oliveira, T. C., Rodrigues, R. A. e Parizi, R. B. (2012) Caféboo: um jogo para auxiliar a aprendizagem nas operações básicas de matemática. In: Anais dos Workshops do CBIE.

Pierini, L.(2012) Brinquedos Numéricos: um jogo para o ensino dos conjuntos numéricos. Anais do $23^{\circ}$ Simpósio Brasileiro de Informática na Educação (SBIE 2012), 26-30.

Pinho, M. S. e Eliasquevici, M. K. (2008) PitágorasNet: Um protótipo de objeto de aprendizagem para o ensino de Matemática. CONGRESSO DA SOCIEDADE BRASILEIRA DE COMPUTAÇÃO, 28., 2008, Belém-PA. “Anais...”, p. 245-254.

Reis, C. (2001) Caracterização de um modelo de processo para projetos de software livre. Dissertação (Mestrado) — Instituto de Ciências Matemáticas e de Computação, São Carlos, São Paulo.

Rocha, E. M. e Moreira, M. M. (2011) O Uso do Software Elica no Ensino de Geometria Espacial: relato de experiência. In: Anais do WIE.

Rocha, E.M., Santiago, L.M.L., Lopes, J.O., Andrade, V. S., Moreira, M. M., Souza, T. G., Barroso, A. M. e BORGES NETO, H.. (2008) O uso do GeoGebra nas aulas de Matemática: uma reflexão centrada na prática. In: Anais do SBIE.

Rolino, J.V., Afini, D. C. e VIEIRA, G. B. (2015) Pirâmide Multiplicativa: um jogo sério para a memorização da tabuada. In: Anais do SBIE.

Santos, W. O., Da Silva, A. P. e Silva Junior, C. G.. (2014) Conquistando com o Resto: Virtualização de um Jogo para o Ensino de Matemática. In: Anais do Simpósio Brasileiro de Informática na Educação. p. 317-321.

Santos, W. O., Silva, D. B. F., Santos Júnior, J. J., Bittencourt, I. I. e Silva Junior, C. G. (2015) Desafios com Palitos: Um Jogo Para o Ensino de Conceitos Específicos de Matemática. In: Anais dos Workshops do CBIE.

Sena, D. M., Oliveira, E. H. T. e Carvalho, L. S. G. (2014) Questions Today: Sistema m-learning como auxílio ao ensino da matemática. In: Anais do WIE.

Ventura, M. M. (2007). O Estudo de Caso como Modalidade de Pesquisa. Revista SOCERJ, 20 (5), 383-386. 